\title{
海南省农村多维贫困及影响因素的空间分异
}

\author{
张金萍, 林丹,周向丽, 余珍金金, 宋 伟, 程叶青* \\ (海南师范大学地理与环境科学学院, 海口 571158)
}

\begin{abstract}
摘 要: 贫困具有多维属性, 根据不同社会群体和背景从多维视角定义贫困已成为贫困问题研究的共识。依据 $\mathrm{Al}-$ kire-Foster多维贫困框架, 拓展精准扶贫的“两不愁, 三保障”识别标准, 建立了涵盖教育、健康、居住、生活和收人指 标的海南省农户多维贫困评估指标体系, 基于海南省 70 个乡镇、134 个贫困村 3924 户人户调查数据, 采用双重临 界值法评估了农户及村域多维贫困状况，进而运用地理加权回归(Geographically Weighted Regression, GWR)模型， 分析了村域多维贫困影响因素的空间分异。结果显示, 调查农户多维贫困率达 $18.22 \%$, 多维贫困程度严重的村多 维贫困发生率不一定高, “两不愁、三保障”及收人指标对多维贫困指数的贡献率低。中、西部连片贫困地区多维贫 困主要表现为较差的资产状况、不清洁的炊事燃料、较高的家庭成员患病率和较低的家庭成员最高学历。GWR 模 型分析表明,作为多维贫困最重要的影响因素, 户主性别、户主受教育水平、女性劳动力占比和抚养比 4 个变量估 计系数的空间分异明显。总体上,女性户主和低学历户主为主的地区倾向于更易发生多维贫困,二者的影响分别 表现为从东到西、从北到南有所增强。女性劳动力占比为负向影响, 抚养比为正向影响, 呈现出自北向南增强的趋 势,体现了海南贫困地区劳动力弱、女性相对更勤劳等典型地域特征。
\end{abstract}

关 键 词:多维贫困; Alkire-Foster法;GWR;空间异质性;海南省

科学定义和衡量贫困是一项具有重要政策含 义且需高度关注的研究课题 ${ }^{[1]}$ 。长期以来, 大多数 国家(地区)使用收人/消费方法定义贫困, 减贫措施 以收人增长为中心而不是以人为中心 ${ }^{[2]}$, 忽视了一 个人既是经济人, 同时也是社会人、道德人和政治人 的关键问题 ${ }^{[3]}$ 。贫困因其多维性而难以客观定义 ${ }^{[4]}$, 但是, 学者普遍认为, 贫困深深根植于区域社会、经 济和政治结构, 且往往与区域、国家和国际层面的 社会、政治和经济变化有关 ${ }^{[5]}$ 。因而, 贫困的定义必 须与特定社会、文化、历史背景和特定时期社会生 活标准相关联 ${ }^{[3]}$ 。

已有研究大多采用基于双重临界值法(AlkireFoster 法, A-F 法)的多维贫困指数(multidimensional poverty index, MPI)界定贫困 ${ }^{[6-7]}$, 依据所研究问题选 择合适的指标。MPI 推进了 $\operatorname{Sen}^{[8]}$ 的研究, 有说服力 地辨明了更全面的贫困概念和能力贫困的衡量标 准 ${ }^{[9]}$, 反映了剥夺的联合分布及对贫困程度的敏感 性 ${ }^{[10]}$, 且不需要对各指标进行农村一城市价格、通 货膨胀或购买力平价等额外调整 ${ }^{[6]}$, 以简单而直接 的方法评估人们在社会权利或有价值的目的中满 足最低国际标准的程度 ${ }^{[1]}$ 。基于上述特点, MPI 已 被广泛用于创建特定社会多维贫困衡量标准, 选择 致贫因素、指标维度和临界值 ${ }^{[12]}$, 以及南部非洲 ${ }^{[13]}$ 、 南亚 ${ }^{[14]}$ 、拉丁美洲 ${ }^{[15]}$ 等世界贫困人口集中地区多维 贫困问题的研究实践。

中国长期重视扶贫开发和消除贫困,致力于贫

收稿日期: 2020-01-08; 修订日期:2020-05-09。

基金项目: 国家自然科学基金项目(41661028,41761118); 海南省自然科学基金项目(417099,418MS052);海南省自然科学基金 高层次人才项目(2019RC178);2019年海南省普通高等学院研究生创新科研课题(Hys2019-240)。[Foundation: National Natural Science Foundation of China, No. 41661028 and 41761118; Natural Science Foundation of Hainan Province, No. 417099 and 418MS052; High- level Talent Project of Natural Science Foundation of Hainan Province, No. 2019RC178; Innovative Research Project for Postgraduates of Hainan Province in 2019, No. Hys2019-240. ]

第一作者简介: 张金萍(1977一), 女, 山东招远人,博士, 副教授, 主要研究方向为乡村地理学。E-mail: maryzhjp@126.com *通信作者简介: 程叶青(1976-), 男,湖南武冈人,博士,教授, 主要研究方向为乡村地理学。E-mail: 34794249@qq.com 
困农户收人提升目标的减贫成效显著,但贫困面不 断变化给全面消除绝对贫困带来了挑战 ${ }^{[16]} 。 2014$ 年始, 中国实施精准扶贫战略, 确定了以“两不愁、 三保障”为主, 家庭年人均纯收人为辅的贫困人口 精准退出标准, 意味着中国对贫困的理解由单维转 向多维。然而,该标准并未涵盖福祉的所有方面, 有必要使用更为广泛的福祉观, 从多维视角对贫困 进行定义和测度，以便制定更有成效的减贫方案。 诸多学者采用多样化的指标系统对中国多维贫困 进行了大量研究, 普遍发现基于多维视角的贫困发 生率一般远高于基于单一收人维度的贫困发生率， 中国农村相比城市而言有更高的多维贫困发生率, 多维贫困家庭的主要致贫因素随研究区和指标不 同而迥异 ${ }^{[17-21]}$ 。

海南省是中国中西部 22 个扶贫开发重点省份 之一, 所属 19 个市县(区) 中有 5 个国家扶贫开发工 作重点市县、63.98 万农村建档立卡贫困人口 ${ }^{(1)}$ 。有 别于其他扶贫开发重点省区, 海南省自然资源丰 富, 生态环境良好, 是中国重要的冬季蔬菜、热带水 果和热带经济作物产区 ${ }^{[22]}$ 。全省贫困人口总量不 大, 但贫困市县的贫困发生率较高, 农户家庭特征 及贫困发生机制区域分异明显 ${ }^{[23]}$ 。国家统计局全 国农村贫困监测调查数据显示, 海南农村贫困发生 率从 2013 年的 $11.1 \%$ 下降至 2018 年的 $1.3 \%$, 减贫 成效显著。然而, 海南贫困人口仍然面临物质或金 融资产少、传统种植和养殖业依赖严重、低薪低技 术含量、繁重体力劳动及不规律零散务工维持生存
或改善生计状况等问题。此外,由于受教育水平普 遍较低,贫困人口通过劳动力市场积累自身发展资 本非常困难 ${ }^{[2]}$, 基于亲属和邻居关系构建的社交网 络因亲属和邻居生活状况同样不佳而难以为贫困 人口稳定脱贫提供有效帮助, 大多数脱贫人口即使 能满足 “两不愁、三保障”标准, 仍然有着较大的生 计压力和返贫风险 ${ }^{[25]}$ 。

因此,在着力解决 “两不愁、三保障”问题的脱 贫攻坚战略已取得显著成效的背景下,有必要集成 反映生活质量的若干指标, 从更广泛福祉观的视角 科学认知地方贫困状况。本文构建改进的多维贫 困测度指标体系,运用 A-F 法对海南 3924 户农户的 多维贫困状况进行评价, 进而在村域尺度上, 从农 户家庭特征和地理区位特征的视角分析多维贫困 影响因素的空间分异, 为更为精准地识别贫困人口 和制定更有针对性的减贫政策措施提供决策参考。

\section{1 研究方法与数据}

\section{1 研究方法}

\subsection{1 多维贫困测算方法}

依据联合国开发计划署(UNDP)与英国牛津大 学人类发展中心 $(\mathrm{OPHI})$ 合作开发的多维贫困指数 (MPI)框架, 基于中国精准扶贫贫困人口识别和退 出的“两不愁、三保障”标准,适当调整教育、健康和 生活子系统的具体指标, 构建海南农户多维贫困测 度指标体系(表1)。该指标体系涵盖了教育保障、基

表 1 海南省农户多维贫困测度的指标体系

Tab.1 Index system of multidimensional poverty measurement for rural households in Hainan Province

\begin{tabular}{|c|c|c|c|}
\hline 子系统 & 指标 & 剥夺临界值 $Z$ & 指标描述 \\
\hline \multirow[t]{2}{*}{ 教育 } & 家庭成员最高学历 & 1 & 初中以下赋值为 1 , 初中及以上为 0 \\
\hline & 儿童就学情况* & 1 & 家中义务教育阶段辍学儿童 $\geqslant 1$ 赋值为 1 , 否则为 0 \\
\hline \multirow[t]{2}{*}{ 健康 } & 购买新农合保险情况* & 1 & 家庭成员中未购买人数 $\geqslant 1$ 赋值为 1 ,否则为 0 \\
\hline & 患病情况 & 1 & 家中大病或长期慢性病患者或残疾人 $\geqslant 1$ 赋值为 1 , 否则为 0 \\
\hline 居住 & 安全住房 ${ }^{*}$ & 1 & 居住在危房中或无住房或人均住房面积 $<10 \mathrm{~m}^{2}$ 赋值为 1 , 否则为 0 \\
\hline \multirow[t]{5}{*}{ 生活 } & 营养状况* & 1 & 缺口粮或每月吃蛋白质食品 $\leqslant 1$ 次赋值为 1 ,否则为 0 \\
\hline & 穿衣状况" & 1 & 无应季换洗衣服、被裖、鞋赋值为 1 ,否则为 0 \\
\hline & 冲水则所 & 1 & 家中没有冲水则所赋值为 1 ,否则为 0 \\
\hline & 炊事燃料 & 1 & 使用畜禽粪便或柴草、木炭等薪柴等非清洁能源赋值为 1 , 否则为 0 \\
\hline & 资产状况 & 1 & $\begin{array}{l}\text { 拥有冰箱、电视机、空调、电热水器、电磁炉、洗衣机、电脑、电饭锅、电话等家用电器 } \\
\text { 数量 } \leqslant 1 \text { 或自行车、电动车、摩托车、小汽车等交通工具数量 }<1 \text { 赋值为 } 1 \text {, 否则为 } 0\end{array}$ \\
\hline 收人 & 家庭年人均纯收人* & 3523 & $\leqslant 3523$ 元赋值为 1 , 否则为 0 \\
\hline
\end{tabular}

注: 2018 年海南省扶贫标准线为农村家庭年人均纯收人 3523 元; 带*的为精准扶贫重点关注的“两不愁、三保障”及收人指标。

(1) 数据来自海南省扶贫办公室。 
本医疗、住房安全、生活质量和收人水平等最基本 减贫指标。其中,生活质量除了刻画“不愁吃、不愁 穿”的营养状况和穿衣状况指标, 增加了冲水则所、 炊事燃料和家庭资产状况等指标。鉴于指标的重 要性很难客观分级, 本文采用通用的等权法赋权 重, 即权重均为 1 。

运用A-F法(表 2)对农户进行多维贫困识别, 即 当农户某个指标得分达到剥夺临界值 $Z$ 时, 表明农 户该指标被剥夺, 被剥夺的指标数量大于等于 $k$ 时, 该农户属性识别为多维贫困。采用维度 “加总一分 解” 的方法, 先 “加总” 得到村域尺度上评价农户多 维贫困程度的多维贫困指数 $\operatorname{MPI}(k)$; 再 “分解” 得 到各指标和子系统的贡献率。

\subsection{2 地理加权回归模型}

贫困数据通常存在空间非平稳性。因此, 采用 地理加权回归(Geographically Weighted Regression, GWR)模型研究多维贫困及其影响因素 ${ }^{[26]}$ 。首先, 建立 134 个调研村点数据的 Voronoi 图, 表达村域之 间的邻接关系, 基于一阶 Queen 邻接规则构建空间 权重矩阵。其次, 以村域多维贫困指数 MPI 为因变 量, 以地理区位特征(包括村庄到县城的可达性、村 庄的平均高程)和农户家庭特征(包括民族、户主年 龄、户主性别、户主受教育水平、家庭规模、抚养比、 性别比、劳动力占比、女性成员占比、女性劳动力占 比、单位劳动力供养学生数、人均耕地、就业类型) 为自变量, 采用最小二乘法(OLS)笁选显著变量。 最后, 针对少量显著变量分别建立 OLS 和 GWR 模 型, 分析模型残差全局 Moran's $I$ 值的变化, 如果
GWR 模型能去除变量的空间非平稳性,则利用 GWR 模型分析各变量对村域多维贫困的影响。

\section{2 数据来源与处理}

根据已构建的海南省农户多维贫困测度指标 体系,参考中国 2020 年减贫目标和国际反贫困计划 关注的重点,考虑海南社会经济和文化发展背景设 计调查问卷。主要包括农户的区位特征、家庭特 征、收人水平与构成、教育、住房、医疗、生活质量以 及重要减贫政策实施效果等情况。

数据主要来源于 2018 年 11 月 12 日至 12 月 15 日进行的实地调研和问卷调查。首先, 参考贫困发 生率、贫困人口规模、空间分布情况和地区特征, 从 海南省 19 市(县、区)中各选择 $3 \sim 5$ 个乡镇, 每个乡镇 选择 1 2 个村, 共计选择 70 个乡镇 134 个村作为样 本区(图 1)。其次, 从海南省扶贫办提供的 2018 年 精准扶贫大数据平台, 随机抽取各抽样村被调查建 档立卡农户的名单。人村实地调查中随机抽取部 分非建档立卡人口的五保户和低保户样本。其三, 对所有抽样农户进行人户问卷调查和面对面深度 访谈, 最终获取的问卷调查总样本量为 3924 户, 其 中建档立卡脱贫户 2637 户,贫困户 348 户,非建档 立卡户939户。

\section{2 多维贫困的空间分异}

\section{1 单维贫困状况}

从单维贫困状况来看, 有 $76.3 \%$ 的被调查农户

表 2 多维贫困测算的变量及方法

Tab.2 Variables and methods of multidimensional poverty measurement

\begin{tabular}{|c|c|}
\hline 变量 & 计算方法 \\
\hline 剥夺临界值 $Z$ & 各指标的贫困标准 $z_{j}, j=1,2, \cdots, d$, 其中 $d$ 为指标数量 \\
\hline 加权剥夺矩阵 $\boldsymbol{G}_{w}$ & $g_{i j}(i=1,2, \cdots, n ; j=1,2, \ldots, d)$ 表示第 $i$ 个农户在第 $j$ 指标上是否被剥夺, 如果第 $i$ 个农户的第 $j$ 个指标的观测值低 \\
\hline & 于 $z_{j}$ 则赋值为 1, 否则赋值为 $0 ;$ 加权后的剥夺矩阵为 $G_{w}, w_{j}$ 为第 $j$ 个指标的权重, $\sum_{i=1}^{d} w_{j}=10$ \\
\hline 被剥夺指标数 $k$ & $k$ 表示农户贫困维度总数, $1 \leqslant k \leqslant d, k$ 的取值一般介于 $2 \sim d$ 之间 \\
\hline 多维贫困剥夺矩阵 $\boldsymbol{C}$ & $c_{i j}(k)=\left\{\begin{array}{ll}\sum_{j=1}^{d} g_{i j} w_{j} & \sum_{j=1}^{d} g_{i j} w_{j} \geqslant k \\
0 & \text { 其他 }\end{array} \quad(k=1,2,3, \cdots, d)\right.$ \\
\hline 多维贫困个体剥夺矩阵 $\boldsymbol{Q}$ & $q_{i j}(k)= \begin{cases}1 & c_{i j}(k)>0 \\
0 & \text { 其他 }\end{cases}$ \\
\hline 多维贫困率 $H(k)$ & $H(k)=\sum_{i=1}^{n} q_{i j}(k) / n, n$ 为研究区域农户总数 \\
\hline 平均剥夺份额 $A(k)$ & $A(k)=\sum_{i=1}^{n} c_{i j}(k) / \sum_{i=1}^{n} q_{i j}(k) \times d$ \\
\hline 多维贫困指数 MPI $(k)$ & $\operatorname{MPI}(k)$ 表示研究区域多维贫困状况 , $\operatorname{MPI}(k)=H(k) \times A(k)$ \\
\hline 指标贡献率 $\lambda_{j}(k)$ & $\lambda_{j}(k)=\sum_{i=1}^{m} g_{i j}(k) / \sum_{i=1}^{m} \sum_{j=1}^{d} g_{i j}(k)$, 其中 $m$ 表示第 $k$ 维贫困情况下被剥夺的农户数量 \\
\hline
\end{tabular}


至少在 1 项指标上被剥夺。主要致贫原因来自于健 康、生活和教育, 而收人子系统贫困率为 $7.3 \%$, 列末 位(表 3)。39.6\%的农户有患大病/长期慢性病的家 庭成员或残疾人, 成为海南省农户贫困最主要的原 因。炊事燃料方面，由于清洁能源的成本更高， $31.5 \%$ 的农户仍然保持经常使用柴草烧水、做饭的 习惯。 $25.7 \%$ 的农户在资产状况维度被剥夺, 被访 农户普遍拥有电饭锅和电视等家用电器, 主要交通 工具为摩托车和电动自行车。家庭成员最高学历 为小学及以下的农户占 $20.5 \%$, 教育水平低成为限 制农户脱贫的重要原因。但是, 精准扶贫所关注的 “两不愁、三保障”及收人维度已经不存在严重的剥 夺。从村域分布来看(图 2), 57\%的被调研村庄都以 家中有患大病/慢性病或残疾人口为主要剥夺维度, 空间上遍布全省大部分地域。以炊事燃料和资产 状况为第一剥夺维度的村合计占 $34 \%$, 主要分布在 海南省中部和西部地区。

\section{2 多维贫困状况}

在各指标等权情况下,农户存在着 1 8 个维度

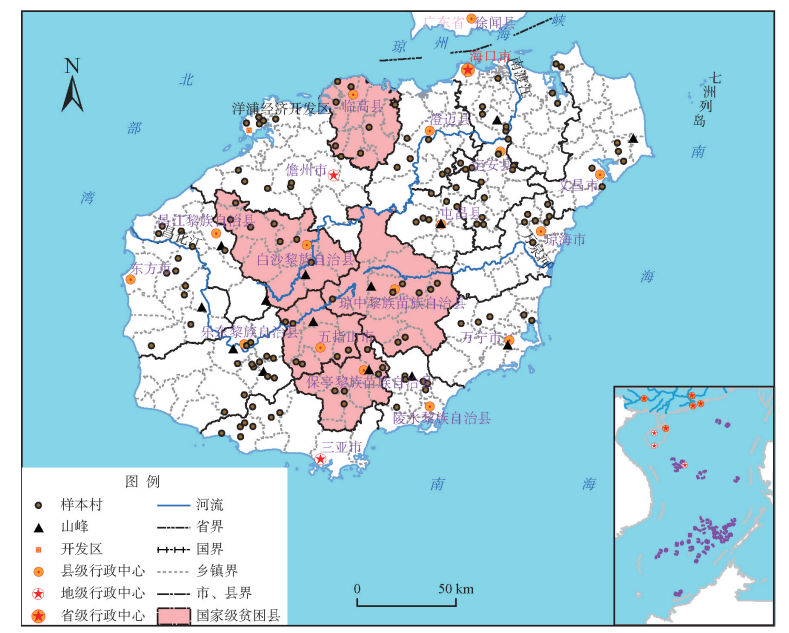

注: 本图基于海南测绘地理信息局标准地图服务网站下载的 审图号为琼 S(2019)054号的标准地图制作, 底图无修改。下同。

图 1 样本村分布

Fig.1 Distribution of sample villages
被剥夺的现象(表 4$)$ 。根据《人类发展报告》,样本家 庭 $\geqslant 1 / 3$ 的指标被剥夺即为多维贫困, 故对 $k=3$ 时的 村域多维贫困状况进行分析。 $k=3$ 时,调查农户的 多维贫困率 $H$ 为 $18.22 \%$, 平均剥夺份额 $A$ 为 0.3195 , 而不满足 “两不愁、三保障”及收人标准的贫 困农户仅占 $9.25 \%$, 说明多维贫困率较高, 程度较 深。从 $k=3$ 时 $H 、 A$ 和 MPI的空间分布来看(图 3), 多 维贫困率 $H$ 高于 $18.22 \%$ 和多维贫困指数 MPI 高于 0.0582 的村集中分布在海南省中部和西南部。平 均剥夺份额 $A$ 高于 0.3195 的村分布相对零散。 $A$ 高 但 $H$ 不高的村有 16 个,这些村多维贫困率平均仅为 $10.23 \%$, 虽然只有少量多维贫困人口, 但户均有 3.97 个维度被剥夺, 甚至略高于 $H$ 和 $A$ 双高村的户 均剥夺维度数 (3.90), 说明少量村庄多维贫困率虽 然不高, 但是多维贫困的程度较深。

由表 5 可知, $k=3$ 时, MPI 贡献率超过 10\%的指 标依次为资产状况、炊事燃料、家庭成员患病情况 和家庭成员最高学历。因此, 较低的生活水平和较 多的患病人口是现阶段调查村多维贫困面临的主 要问题。持续推进的危房改造政策较大地改善了 农户居住条件, 住房存在安全隐患的农户仅占 $0.86 \%$,无住房或住房面积偏小者仅占 $8.7 \%$,拉高了 该指标贡献度。收人对 MPI 的贡献率相对较低, 仅 有 $7.72 \%$, 其他“两不愁、三保障”指标的贡献率则更 低,进一步印证了精准扶贫政策实施所取得的巨大 成效。MPI 贡献率超过 10\%的指标在空间上均呈 现出一定的空间集聚特征(图 4)。家庭成员最高学 历贡献率大的村在空间上大致呈以中部山区为圆 心的圆环状分布, 中东部的屯昌一琼海一万宁一带 和西南部东方一乐东一带是主要集聚区。患病情 况贡献率大的村主要集中在海南岛南部地区, 患大 病和长期慢性病的农户偏多。炊事燃料贡献率大 的村连片分布在海南省西部和临高一万宁沿线地 区, 其林地较多, 农户炊事使用柴草的现象更多 见。资产状况贡献率大的村集中连片分布在中部 地区, 资产拥有率偏低是贫困的主要表现。

表3 被调查农户单维贫困率

Tab.3 Unidimensional poverty incidence of surveyed rural households

\begin{tabular}{|c|c|c|c|c|c|c|c|c|c|c|c|}
\hline \multirow[b]{2}{*}{ 子系统 } & \multicolumn{2}{|c|}{ 教育 } & \multicolumn{2}{|c|}{ 健康 } & \multirow{2}{*}{$\begin{array}{l}\text { 居住 } \\
\text { 安全 } \\
\text { 住房 }\end{array}$} & \multicolumn{5}{|c|}{ 生活 } & \multirow{2}{*}{$\begin{array}{c}\text { 收人 } \\
\text { 家庭年人均 } \\
\text { 纯收人 }\end{array}$} \\
\hline & $\begin{array}{l}\text { 家庭成员 } \\
\text { 最高学历 }\end{array}$ & $\begin{array}{c}\text { 儿童就学 } \\
\text { 情况 }\end{array}$ & $\begin{array}{c}\text { 新农合 } \\
\text { 情况 }\end{array}$ & $\begin{array}{l}\text { 患病 } \\
\text { 情况 }\end{array}$ & & $\begin{array}{l}\text { 营养 } \\
\text { 状况 }\end{array}$ & $\begin{array}{l}\text { 穿衣 } \\
\text { 状况 }\end{array}$ & $\begin{array}{l}\text { 冲水 } \\
\text { 则所 }\end{array}$ & $\begin{array}{l}\text { 炊事 } \\
\text { 燃料 }\end{array}$ & $\begin{array}{l}\text { 资产 } \\
\text { 状况 }\end{array}$ & \\
\hline 剥夺农户数量/户 & 803 & 17 & 6 & 1554 & 389 & 13 & 19 & 390 & 1237 & 1010 & 285 \\
\hline 贫困率/\% & 20.5 & 0.4 & 0.2 & 39.6 & 9.9 & 0.3 & 0.5 & 9.9 & 31.5 & 25.7 & 7.3 \\
\hline
\end{tabular}




\section{3 多维贫困的影响因素}

\subsection{GWR 模型效果}

对 MPI有显著影响的变量为户主性别 $x_{1}$ 、户主 受教育水平 $x_{2}$ 、女性劳动力占比 $x_{3}$ 和抚养比 $x_{4}$, 其量 化方法和统计特征见表 6 。分析估计结果, OLS 模 型残差的 Moran's $I$ 呈显著的正相关(表 7), 表明多 维贫困与其影响因素不再满足 OLS 法要求的村之 间相互独立的假设, OLS 回归模型的结果不可信。 相比而言, GWR 模型残差的 Moran's $I$ 已不能通过 $5 \%$ 的显著性检验，说明去除了残差的自相关。并 且, GWR 模型有效缩减了残差平方和, AICc 的下降 值远大于 $3, R^{2}$ 和调整 $R^{2}$ 值也得到显著改善, 说明拟 合程度比 OLS 模型显著提高。从局部 $R^{2}$ 来看, GWR 模型能够反映多维贫困总变异的 $16.67 \%$ $40.57 \%$ 。观察局部 $R^{2}$ 的空间变异(图 5), 发现东部

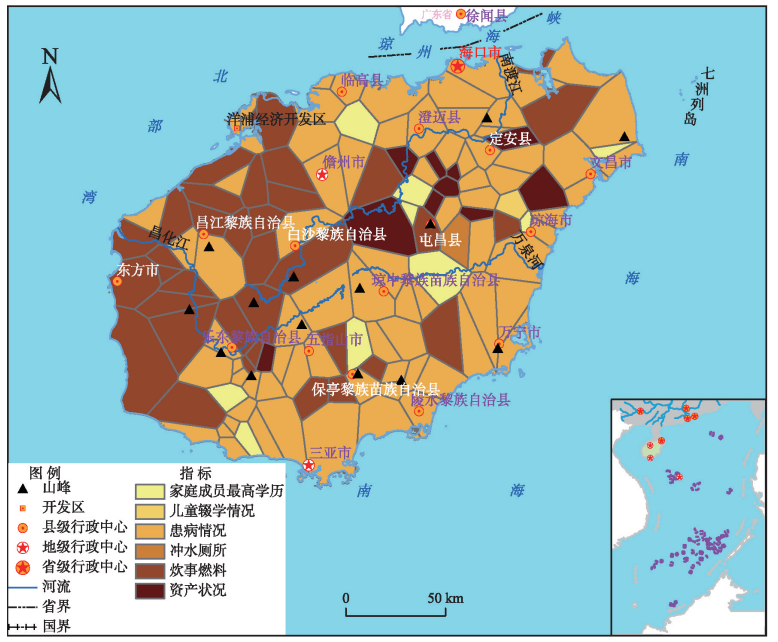

图 2 单维贫困主要剥夺维度的村域分布

Fig.2 Distribution of the major dimensions of deprivation in unidimensional rural poverty
地区拟合优度最高, 可以更好地被模拟;西北部向 中部延伸地区拟合优度较低,多维贫困可能还受其 他因素的影响。

\section{2 影响因素的空间分异}

模拟结果(图6、表 7)显示, 户主对带领家庭脱 贫具有重要作用,农户中反映女性、老人、儿童的指 标对多维贫困具有重要影响。调查村户主性别和 户主受教育水平都对多维贫困有显著影响。已有 研究认为,女性户主家庭倾向于更加贫困 ${ }^{[27]}$ 。本文 设定户主性别的系数为正, 表明户主越趋向于女 性,多维贫困现象越明显。GWR模型显示, 大部分 被调查村该变量均为正系数。然而,在中部的屯 昌、琼中到沿海的万宁一带,户主性别的影响为负, 表明男性户主为主的村更易发生多维贫困。调研 发现,这些村的男性户主家庭大多脱贫致富的内生 动力不强, 不喜辛苦劳作, 偏爱自由自在的生活。 户主受教育水平对绝大多数被调查村的多维贫困 指数为负向影响, 与预设相符, 且在西南地区的影 响最为明显。北部市县户主受教育水平虽然呈现 出较弱的正向影响,但该区域户主学历仍以文盲、

表 4 不同 $\boldsymbol{k}$ 值下的多维贫困测算结果

Tab.4 Measurements and contribution of each subsystem under different k-values

\begin{tabular}{cccc}
\hline$k$ & 多维贫困率 $H / \%$ & 平均剥夺份额 $A$ & 多维贫困指数 MPI \\
\hline 1 & 76.33 & 0.1725 & 0.1317 \\
2 & 40.93 & 0.2431 & 0.0995 \\
3 & 18.22 & 0.3195 & 0.0582 \\
4 & 6.45 & 0.4050 & 0.0261 \\
5 & 2.17 & 0.4866 & 0.0105 \\
6 & 0.54 & 0.5844 & 0.0031 \\
7 & 0.18 & 0.6623 & 0.0012 \\
8 & 0.05 & 0.7273 & 0.0004 \\
\hline
\end{tabular}
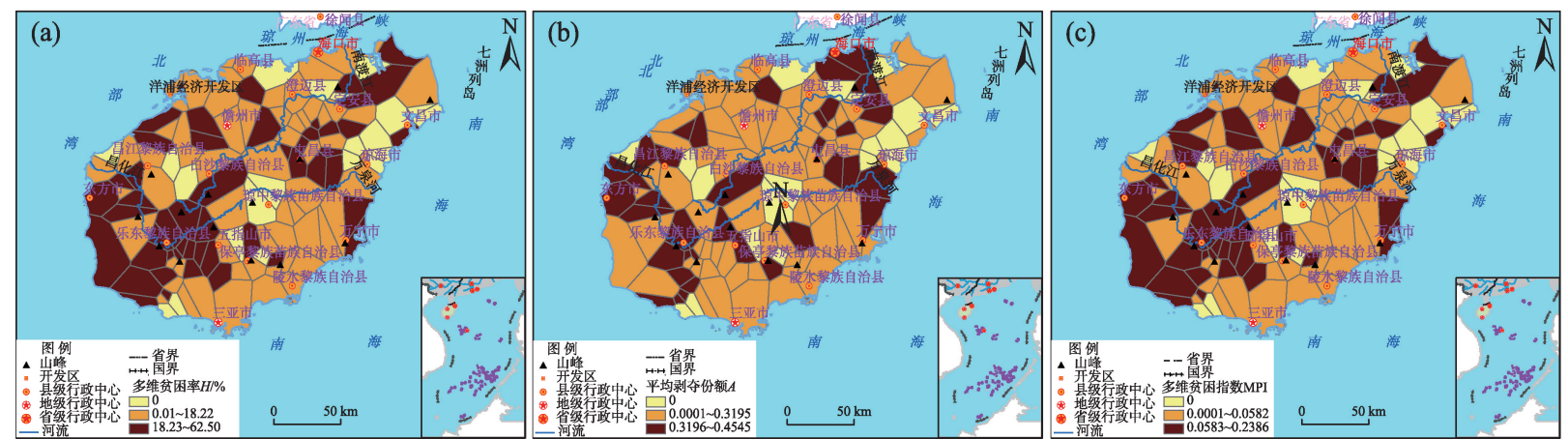

图 3 多维贫困率 $H$ 、平均剥夺份额 $A$ 和多维贫困指数 MPI的空间分布 $(k=3)$

Fig.3 Distribution of the multidimensional poverty ratio, the average deprivation share, and the multidimensional poverty index values 
表 5 不同指标对多维贫困指数的贡献率 $(k=3)$

Tab.5 Contribution of the indicators to the multidimensional poverty index

$(\%)$

\begin{tabular}{|c|c|c|c|c|c|c|c|c|c|c|c|}
\hline \multirow[b]{2}{*}{ 子系统 } & \multicolumn{2}{|c|}{ 教育 } & \multicolumn{2}{|c|}{ 健康 } & \multirow{2}{*}{$\begin{array}{l}\text { 居住 } \\
\text { 安全 } \\
\text { 住房 }\end{array}$} & \multicolumn{5}{|c|}{ 生活 } & \multirow{2}{*}{$\begin{array}{c}\text { 收人 } \\
\text { 家庭年人均 } \\
\text { 纯收人 }\end{array}$} \\
\hline & $\begin{array}{l}\text { 家庭成员 } \\
\text { 最高学历 }\end{array}$ & $\begin{array}{c}\text { 儿童就学 } \\
\text { 情况 }\end{array}$ & $\begin{array}{c}\text { 新农合 } \\
\text { 情况 }\end{array}$ & $\begin{array}{l}\text { 患病 } \\
\text { 情况 }\end{array}$ & & $\begin{array}{l}\text { 营养 } \\
\text { 状况 }\end{array}$ & $\begin{array}{l}\text { 穿衣 } \\
\text { 状况 }\end{array}$ & $\begin{array}{l}\text { 冲水 } \\
\text { 则所 }\end{array}$ & $\begin{array}{l}\text { 炊事 } \\
\text { 燃料 }\end{array}$ & $\begin{array}{l}\text { 资产 } \\
\text { 状况 }\end{array}$ & \\
\hline 贡献率 & 14.88 & 0.36 & 0.24 & 18.27 & 8.83 & 0.52 & 0.76 & 9.39 & 19.14 & 19.90 & 7.72 \\
\hline 合计 & \multicolumn{2}{|c|}{15.24} & \multicolumn{2}{|c|}{18.50} & 8.83 & & & 49.70 & & & 7.72 \\
\hline
\end{tabular}
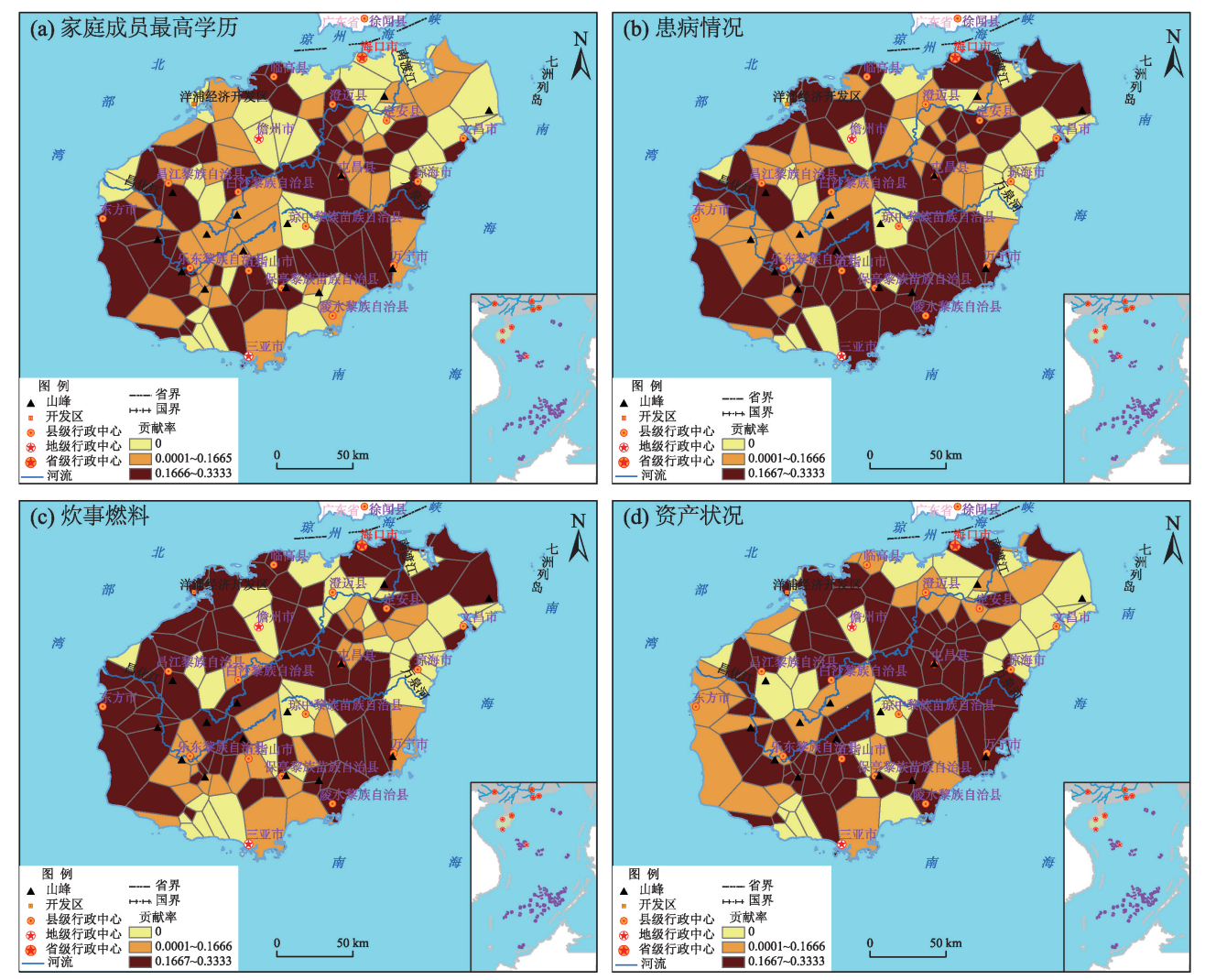

图 4 主要指标对 MPI贡献率的空间分布

Fig.4 Distribution of the contribution of the main indicators to the multidimensional poverty index

表 6 影响因素的变量表示及统计特征

Tab.6 Variable representation and statistical features of influencing factors

\begin{tabular}{|c|c|c|c|c|c|c|}
\hline 变量 & 变量说明 & 预设作用方向 & 最小值 & 最大值 & 平均值 & 中位数 \\
\hline 户主性别 $x_{1}$ & 1 为女性户主家庭, 0 为男性户主家庭 & 正向 & 0 & 1.00 & 0.084 & 0 \\
\hline 户主受教育水平 $x_{2}$ & $\begin{array}{l}\text { 小学及以下为 } 1 \text {, 初中为 } 2 \text {, 高中、职中、职专为 } 3 \text {, 大 } \\
\text { 学及以上为 } 4 \text {; 数值越大表示受教育水平越高 }\end{array}$ & 负向 & 1.00 & 2.33 & 1.621 & 1.630 \\
\hline 女性劳动力占比 $x_{3}$ & 农户女性劳动力占全部劳动力之比 & 正向 & 0.21 & 2.00 & 0.699 & 0.620 \\
\hline 抚养比 $x_{4}$ & $\begin{array}{l}\text { 农户家中单位劳动力供养的 } 60 \text { 岁以上老人和 } 16 \text { 岁 } \\
\text { 以下未成年人数量 }\end{array}$ & 正向 & 0.49 & 3.78 & 1.506 & 1.295 \\
\hline
\end{tabular}

小学和初中为主,具备初中以上学历的仅占 $0.4 \%$ 。 在普遍偏低的文化背景下,即便户主受教育水平稍 高的家庭也不具备摆脱贫困所需要的知识、能力和 素质,因而对多维贫困的影响较弱。

女性劳动力占比和抚养比对多维贫困的影响
也存在明显区位差别。理论上,农村女性在劳动力 市场上受到明显排斥,女性就业者多集中在报酬较 低的领域。女性劳动力占比高的家庭倾向于更加 贫困。然而,在海南省被调研地区, 则表现为相反 的特征。女性劳动力占比越高的村越不易发生多 
表 7 多维贫困影响因素的 OLS 和 GWR 模型估计结果

Tab.7 Estimation results of the ordinary least squares (OLS) and geographically weighted regression

(GWR) models for factors of multidimensional poverty

\begin{tabular}{|c|c|c|c|c|c|c|c|}
\hline \multirow{2}{*}{ 变量 } & \multicolumn{4}{|c|}{ OLS 模型 } & \multirow{2}{*}{ 变量 } & \multicolumn{2}{|c|}{ GWR模型 } \\
\hline & 回归系数 & 标准差 & $t$ 统计值 & $P$ 值 & & 回归系数范围 & 回归系数平均值 \\
\hline 截距 & 0.1358 & 0.0253 & 5.3765 & $0.0007^{* * *}$ & 截距 & $0.0084 \sim 0.1895$ & 0.0957 \\
\hline$x_{1}$ & 0.0529 & 0.0247 & 2.1406 & $0.0342^{* *}$ & $x_{1}$ & $-0.0197 \sim 0.1453$ & 0.0416 \\
\hline$x_{2}$ & -0.0573 & 0.0147 & -3.8948 & $0.0002^{* * *}$ & $x_{2}$ & $-0.0847 \sim 0.0070$ & -0.0370 \\
\hline$x_{3}$ & -0.0985 & 0.0256 & -3.8541 & $0.0002^{* * *}$ & $x_{3}$ & $-0.1812 \sim-0.0275$ & -0.1171 \\
\hline$x_{4}$ & 0.0505 & 0.0110 & 4.5918 & $<0.0001^{* * *}$ & $x_{4}$ & $0.0269 \sim 0.0806$ & 0.0622 \\
\hline$F$ & \multicolumn{4}{|c|}{$11.6624^{* * * *}$} & 局部 $R^{2}$ & \multicolumn{2}{|c|}{$0.1667 \sim 0.4057$} \\
\hline$R^{2}$ & \multicolumn{4}{|c|}{0.2656} & $R^{2}$ & \multicolumn{2}{|c|}{0.4419} \\
\hline 调整 $R^{2}$ & \multicolumn{4}{|c|}{0.2428} & 调整 $R^{2}$ & \multicolumn{2}{|c|}{0.3598} \\
\hline 残差平方和 & \multicolumn{4}{|c|}{0.2249} & 残差平方和 & \multicolumn{2}{|c|}{0.1709} \\
\hline 残差 Moran's I & \multicolumn{4}{|c|}{$0.1746(P=0.0004)$} & 残差 Moran's I & \multicolumn{2}{|c|}{$0.0554(P=0.2190)$} \\
\hline $\mathrm{AICc}$ & \multicolumn{4}{|c|}{781.1336} & $\mathrm{AICc}$ & \multicolumn{2}{|c|}{764.1921} \\
\hline
\end{tabular}

注: ***、**分别表示通过 $0.01 、 0.05$ 水平上的显著性检验。

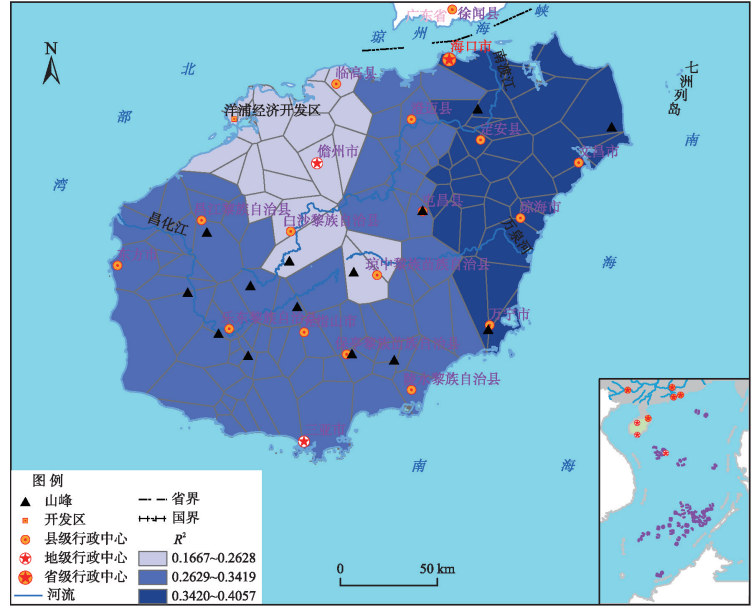

图 5 局部 $R^{2}$ 的空间分布

Fig.5 Spatial distribution of local $R^{2}$

维贫困,且南部地区该变量对多维贫困的影响最为 明显。海南岛由于长期孤悬于海, 至今仍保留着相 对封闭的文化, 宗族观念、男女尊卑有别等思想在 农村地区颇为盛行。贫困村农户多需要女性劳作 来供养家庭, 男性的劳动力市场参与率并未明显高 于女性。再者, 贫困农户收人渠道狭窄, 男性和女 性劳动力的务农收人区分度不高。从务工角度看, 虽然由于工种不同, 不同性别劳动力的日薪或月薪 存在差别, 但海南贫困地区的男性多以不规律的少 量零散打工为主, 女性却表现为更持续的长期打 工, 女性年务工总收人并不明显低于男性。因此, 女性劳动力无论是务农还是务工, 均有效改善了多 维贫困状况。一般来说, 贫困家庭常表现为劳动力
不足, 因此抚养比越高的村越倾向于陷人多维贫 困。GWR 模型的结果与预设相符。南部地区单位 农户平均拥有 0.89 个老人, 0.8 个儿童,但平均劳动 力仅有 0.83 人,平均抚养比达 2.04 。农户单位劳动 力供养的老人和儿童偏多, 劳动力的抚养负担严 重, 是海南南部影响多维贫困的主要因素之一。

\section{4 结论与讨论}

\section{1 主要结论}

本文基于拓展的多维贫困测度指标, 使用 A-F 法, 基于 3924 户农户调查数据评估了海南省贫困人 口集中地区的多维贫困状况,运用 GWR 模型分析 了村域多维贫困影响因素的空间差异。主要结论 如下:

(1) 调查村多维贫困状况和各指标贡献率存在 着明显的空间差异。首先,多维贫困严重的村主要 集中在中部和西南部。但是, 平均剥夺份额高的村 多维贫困率不一定高, 二者存在一定的错位, 故多 维贫困率与深度均需要地方政府加以关注。其次, 各指标对多维贫困的贡献率差别明显,但在精准扶 贫政策已经取得显著成效的背景下，“两不愁、三保 障”标准所关注指标的贡献率均较低。第三, 目前 海南调查村多维贫困主要表现为农户资产拥有率 低、炊事燃料不清洁、家庭成员患病率高和家庭成 员学历低。并且,这些指标在空间上均呈现出明显 的空间集聚特征, 尤其是资产状况和炊事燃料,成为 

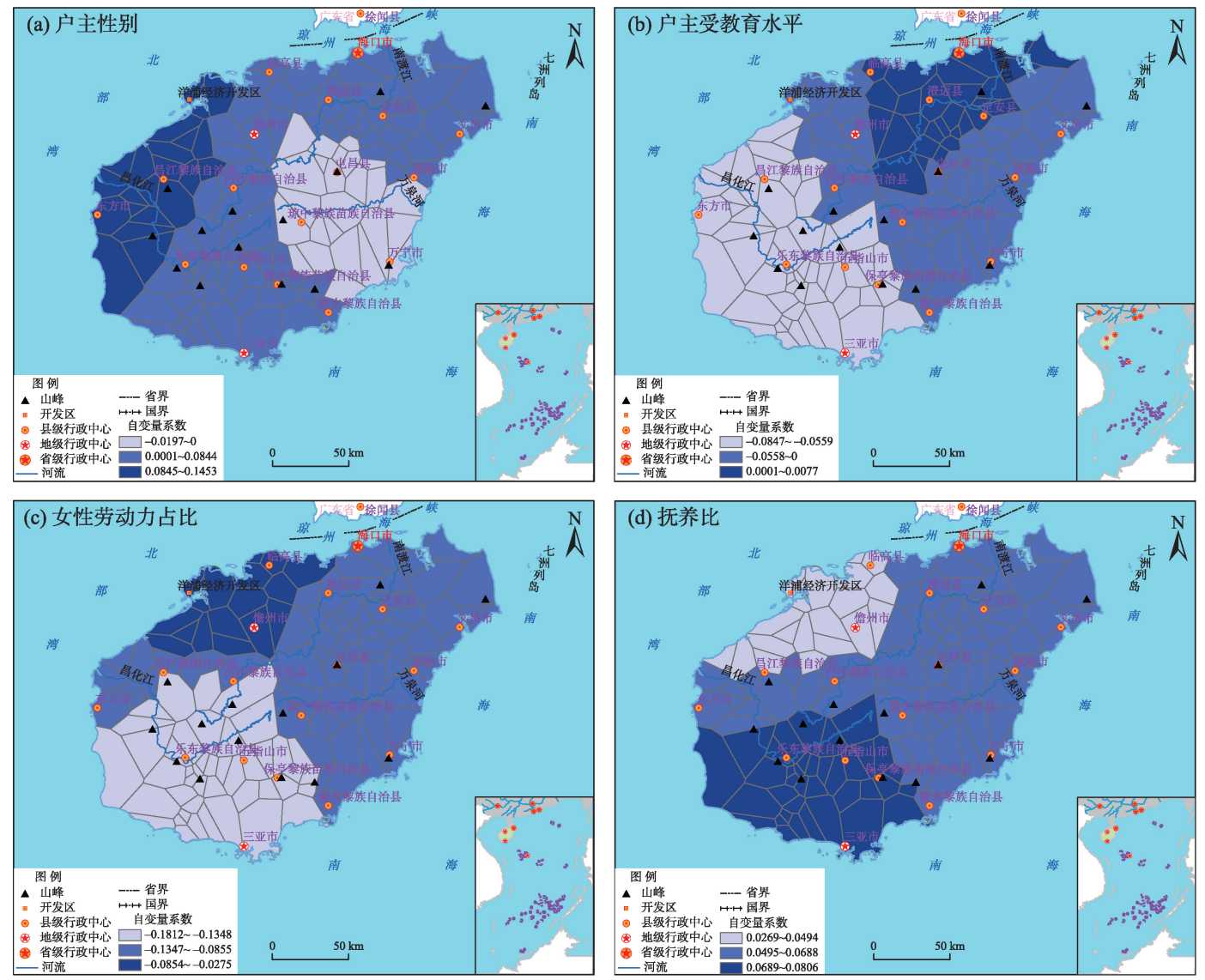

图6 自变量系数估计的空间分布

Fig.6 Spatial variation of the coefficient estimates of independent variables

中部和西部连片地区多维贫困的最主要指标。

(2) 调查村多维贫困受农户家庭属性的综合影 响,但是存在明显的空间分异。户主性别、户主受 教育水平、女性劳动力占比和抚养比 4 个指标对多 维贫困有显著影响。相比 OLS 模型, GWR 模型更 准确地表达了多维贫困影响因素变异的局域特 征。研究发现, 户主性别和户主受教育水平的影响 系数都是正负并存, 且影响从东到西有所增强。少 数村不符合女性户主或者户主受教育水平低的家 庭更贫困的理论, 体现了不同地域农户家庭属性对 多维贫困影响的不均一性。女性劳动力占比为负 向影响, 抚养比为正向影响, 体现了海南贫困地区 劳动力弱、女性相对更勤劳、需要供养的老人和未成 年人偏多等典型特征。在海南南部, 女性劳动力占 比和抚养比是该地区多维贫困最主要的影响因素。

\section{2 讨论}

本文发现，区位特征、民族属性、土地资源拥有 情况、就业等显著影响中国其他省份和地区贫困状 况的变量对海南调查村的多维贫困不构成显著影
响。原因在于,其一, 海南农村的对外社会经济联 系普遍不强,故村庄的地理区位特征对多维贫困没 有显著影响; 其二, 中部地区多为黎族、苗族等少数 民族聚居地区，少数民族村虽然平均收入略低于汉 族村, 但是并未表现出比汉族村更剧烈的多维贫困 特征, 是否少数民族对多维贫困影响不显著; 其三, 抽样调查样本集中于建档立卡户和经济条件较差 的非建档立卡户,这些农户都是村里生计来源较狭 窄、生活质量较差的。他们人均耕地普遍较少且变 异较小, 劳动参与率低且多数务工人员就业类型和 月收人差距不甚明显, 因而土地资源和就业与多维 贫困之间不具有显著的相关性。

为了改善调查村多维贫困状况, 首先, 在户主 受教育水平对多维贫困影响最为明显的西南部和 中部应增加教育投人。不但要引进和培养优良师 资, 还需要加强职业教育、应用型高等教育, 使农户 具备脱贫所需的知识、能力和素质。此外,需要采 用政府自底和社会救助相结合的方式使贫困农户 能以较低的成本获得发展所需的职业技能, 从而破 
除海南贫困地区盛行的重男轻女、因循守旧等落后 文化,增强农户追求美好生活的内生动力。其次, 鉴于农村女性是劳动力市场上的弱势群体, 政府需 要制定相关法规, 确保女性劳动力的就业公平, 这 一点对中部和南部民族地区削弱多维贫困格外重 要。政府还应结合乡村振兴战略, 就地发展特色产 业, 把劳动力留在乡村, 实现劳动力的就地充分就 业和生活质量的稳定改善 ${ }^{[28]}$ 。最后, 应加大对中部 到南部连片地区健康扶贫工作的力度, 对农村居民 定期普及卫生健康知识, 彻底推进则所革命, 敦促 农民养成良好卫生习惯,降低重大疾病和慢性病的 患病率。

本文调查的样本是农村贫困人口集中地区的 建档立卡农户和经济条件较差的非建档立卡农户， 不能完全代表海南农村所有农户的样本。但本文 可为海南贫困群体多维贫困状况的分析提供了一 种农村可持续脱贫攻坚的理论框架。未来, 随着绝 对贫困的逐渐消除, 贫困的多重剥夺现象将成为海 南农村社会经济发展的主要挑战,政府有必要采用 基于多维视角的贫困度量框架对农村贫困进行深 刻洞察和政策制定。

\section{参考文献(References)}

[1] Permanyer I. Assessing individuals' deprivation in a multidimensional framework [J]. Journal of Development Economics, 2014, 109: 1-16.

[2] Scheidel A. Flows, funds and the complexity of deprivation: Using concepts from ecological economics for the study of poverty [J]. Ecological Economics, 2013, 86: 2836.

[3] Gopal P S, Malek N M. Breaking away from the cycle of poverty: The case of Malaysian poor [J]. The Social Science Journal, 2015, 52(1): 34-39.

[4] Osinubi T S. Urban poverty in Nigeria: A case study of Agege area of Lagos State, Nigeria [D]. Ibadan, Nigeria: Faculty of the Social Sciences, University of Ibadan, 2003.

[5] Sulochana N. Poverty in Malaysia: A new look at old problem [M]// Nambiar S. Reassessing poverty in Malaysia. Kuala Lumpur, Malaysia: Wisdom House Publications, 2007: 22-78.

[6] Alkire S, Foster J. Counting and multidimensional poverty measurement [J]. Journal of Public Economics, 2011, 95 (7-8): 476-487.
[7] Alkire S, Foster J, Seth S, et al. Multidimensional poverty measurement and analysis [M]. Oxford, UK: Oxford University Press, 2015: 16-58.

[8] Sen A K. Development as freedom [M]. Oxford, UK: Oxford University Press, 1999: 87-110.

[9] Alkire S, Santos M E. Measuring acute poverty in the developing world: Robustness and scope of the Multidimensional Poverty Index [J]. World Development, 2014, 59: 251-274.

[10] Alkire S, Roche J M, Vaz A. Changes over time in multidimensional poverty: Methodology and results for 34 countries [J]. World Development, 2017, 94: 232-249.

[11] Alkire S, Foster J. Understandings and misunderstandings of multidimensional poverty measurement [J]. Journal of Economic Inequality, 2011, 9(2): 289-314.

[12] Emily J C, Deborah J S, Rupendra N S. Multi-dimensional poverty in Australia and the barriers ill health imposes on the employment of the disadvantaged [J]. The Journal of Socio-Economics, 2011, 40(6): 736-742.

[13] Fransman T, Yu D. Multidimensional poverty in South Africa in 2001-16 [J]. Development Southern Africa, 2019, 36(1): 50-79.

[14] Saboor A, Khan A U, Hussain A, et al. Multidimensional deprivations in Pakistan: Regional variations and temporal shifts $[\mathrm{J}]$. The Quarterly Review of Economics and Finance, 2015, 56: 57-67.

[15] Battiston D, Cruces G, Lopez-Calva L F, et al. Income and beyond: Multidimensional poverty in six Latin American countries [J]. Social Indicators Research, 2013, 112 (2): 291-314.

[16] 刘彦随. 中国新时代城乡融合与乡村振兴 [J]. 地理学 报, 2018, 73(4): 637-650. [Liu Yansui. Research on the urbanrural integration and rural revitalization in the new era in China. Acta Geographica Sinica, 2018, 73(4): 637650. ]

[17] 杨慧敏, 罗庆, 李小建, 等. 生态敏感区农户多维贫困测 度及影响因素分析: 以河南省淅川县 3 个村为例 [J]. 经 济地理, 2016, 36(10): 137-144. [Yang Huimin, Luo Qing, Li Xiaojian, et al. Multidimensional poverty measurement and influencing factor analysis at the households scale of the ecological sensitive area: A case study on three villages of Xichuan County in Henan Province. Economic Geography, 2016, 36(10): 137-144. ]

[18] 文琦, 施琳娜, 马彩虹, 等. 黄土高原村域多维贫困空间 异质性研究: 以宁夏彭阳县为例 [J]. 地理学报, 2018, 73(10): 1850-1864. [Wen Qi, Shi Linna, Ma Caihong, et 
al. Spatial heterogeneity of multidimensional poverty at the village level: Loess Plateau. Acta Geographica Sinica, 2018, 73(10): 1850-1864. ]

[19] Yang J, Mukhopadhaya P. Disparities in the level of poverty in China: Evidence from China family panel studies 2010 [J]. Social Indicators Research, 2017, 132(1): 411450.

[20] Alkire S, Fang Y F. Dynamics of multidimensional poverty and uni-dimensional income poverty: An evidence of stability analysis from China [J]. Social Indicators Research, 2019, 141(3): 25-64.

[21] Lu Y, Routray J K, Ahmad M M. Multidimensional poverty analysis at the local level in northwest Yunnan Province, China: Some insights and implications [J]. Journal of Poverty, 2019, 23(4): 299-316.

[22] 马历, 龙花楼, 屠爽爽, 等. 基于乡村多功能理论的贫困 村域演变特征与振兴路径探讨: 以海南省什寒村为例 [J]. 地理科学进展, 2019, 38(9): 1435-1446. [Ma Li, Long Hualou, Tu Shuangshuang, et al. Characteristics of change and vitalization pathways of poor villages based on multifunctional rural development theory: A case study of Zahan Village in Hainan Province. Progress in Geography, 2019, 38(9): 1435-1446. ]

[23] Zhang J P, Zuo F, Zhou Y M, et al. Analyzing influencing factors of rural poverty in typical poverty areas of Hainan Province: A case study of Lingao County [J]. Chinese Geographical Science, 2018, 28(6): 1061-1076.

[24] 何仁伟, 方方, 刘运伟. 贫困山区农户人力资本对生计
策略的影响研究: 以四川省凉山彝族自治州为例 [J]. 地理科学进展, 2019, 38(9): 1282-1293. [He Renwei, Fang Fang, Liu Yunwei. Influence of human capital on the livelihood strategy of farming households in poor mountainous areas: A case study of Liangshan Yi Autonomous Prefecture of Sichuan, China. Progress in Geography, 2019, 38(9): 1282-1293. ]

[25] 张金萍, 宋伟, 林丹, 等. 海南省连片贫困地区农户致贫 风险分析 [J]. 地理科学, 2020, 40(4): 608-616. [Zhang Jinping, Song Wei, Lin Dan, et al. Risks of poverty of farmers in contiguous poverty-stricken areas in Hainan Province. Scientia Geographica Sinica, 2020, 40(4): 608616. ]

[26] 张金萍, 秦耀辰. 县域粮食单产及其生产投人因素的空 间异质性: 以河南省为例 [J]. 自然资源学报, 2011, 26 (3): 373-381. [Zhang Jinping, Qin Yaochen. Spatial heterogeneity of grain yield per hectare and factors of production inputs in counties: A case study of Henan Province. Journal of Natural Resources, 2011, 26(3): 373-381. ]

[27] Van de Walle D. Lasting welfare effects of widowhood in Mali [J]. World Development, 2013, 51: 1-19.

[28] 程叶青, 翟梦潇, 王芗, 等. 海南省新型城镇化发展模式 及驱动力分析: 以琼海市为例 [J]. 地理科学, 2019, 39 (12): 1902-1909. [Cheng Yeqing, Zhai Mengxiao, Wang Ying, et al. Development model and driving forces of new urbanization in Hainan Province: Qionghai City as a case. Scientia Geographica Sinica, 2019, 39(12): 19021909. ] 


\title{
Spatial difference of multidimensional poverty and its influencing factors in the rural areas of Hainan Province
}

\author{
ZHANG Jinping, LIN Dan, ZHOU Xiangli, YU Zhenxin, SONG Wei, CHENG Yeqing* \\ (College of Geography and Environmental Sciences, Hainan Normal University, Haikou 571158, China)
}

\begin{abstract}
Poverty has multidimensional attributes, and it has become a consensus to study poverty from a multidimensional perspective according to different social groups and backgrounds. In order to measure the multidimensional poverty situation in the rural areas where the poor population is concentrated in Hainan Province, we expanded the index system based on the exit criteria for targeted poverty alleviation fulfilling the basic needs of food and clothing and guaranteeing compulsory education, basic medical care, and housing, and established a multidimensional poverty assessment conceptual model for rural households in Hainan Province that covers education, health, housing, livelihood, and income indicators. Then, based on household survey data from 3924 households in 70 towns and 134 poor villages of Hainan Province in 2018, we used the double threshold Alkire-Foster (A-F) method to evaluate the multidimensional poverty status of rural households and villages, and then used the geographically weighted regression (GWR) model to analyze the spatial heterogeneity of the influencing factors of multidimensional poverty in villages. The study results show that: 1) The incidence of multidimensional poverty of the surveyed households was $18.22 \%$. But the incidence of multidimensional poverty in villages with severe multidimensional poverty is not necessarily high. 2) The four indicators of farming households' asset status, cooking fuels, family members' diseases, and family members' highest academic qualifications contribute the most to multidimensional poverty, while the contribution ratio of indicators belonging to the standard of fulfilling basic needs of food and clothing and guaranteeing compulsory education, basic medical care, and housing, as well as income are generally not high. The multidimensional poverty in the contiguous poverty areas in the central and western regions of the province is mainly manifested by poor asset conditions, unclean cooking fuels, high prevalence of disease of family members, and lower education levels. 3) The GWR model analysis showed that as the most important influencing factors of multidimensional poverty, spatial heterogeneity of the estimated coefficients of the four variables, gender of the household head, education level of the household head, ratio of female labor force, and dependency ratio, have very obvious impacts. In general, areas with more female- headed and low-education attainment individual headed households tend to be more prone to multidimensional poverty, and their impacts increased from east to west and from north to south, separately. With an increasing trend from north to south, the effect of the proportion of female labor force is negative and that of the dependency ratio is positive, which reflects the typical regional characteristics of weak labor force and relatively more industrious women in Hainan povertystricken areas.
\end{abstract}

Keywords: multidimensional poverty; Alkire-Foster (A-F) method; geographically weighted regression (GWR); spatial heterogeneity; Hainan Province 